\title{
FOOD NEOPHOBIA, FAMILIARITY, AND WILLINGNESS-TO-TRY MALAYSIA LOCAL FOODS AMONG SOJOURNERS IN TERENGGANU
}

\author{
Nur Asma Mohd Hafizi ${ }^{1}$, Abdul Wahab Mohamad Rahijan², Fathilah Ismail ${ }^{3}$ \\ \& Wan Zainal Shukri Wan Hafiz ${ }^{4}$ \\ 1,2,4Faculty of Fisheries and Food Science, Universiti Malaysia Terengganu, \\ ${ }^{3}$ Faculty of Economics and Social Development, University Malaysia Terengganu \\ (wanafiz@umt.edu.my)
}

\begin{abstract}
Nowadays, Malaysia has gained more popularity among sojourners either as a destination to continue their study or as a good place to work. However, there are few studies regarding food neophobia among sojourners and information on the subject is limited. The objectives of this study are to determine the level of food neophobia among sojourners in Terengganu, to compared between food neophobia score and social-demographic profile, to examine association of familiarity and willingness-to-try local foods among people with different levels of food neophobia and to examine the relationship between the food neophobia scores and the willingness-to-try new foods and same food neophobia score with familiar foods. A total of 152 questionnaires were distributed to international students from Middle east. The findings reported average food neophobia scale among sojourners in Terengganu was $40.15 \pm 12.21$. There were no significant differences between food neophobia and gender but a significant difference between residential area (urban and rural), and the length of stay in Malaysia. Moreover, there were significant associations between food neophobia and familiarity towards Malaysia's local cuisines. A significant association between food neophobia and willingness-to-try Malaysia local foods was also recorded. The impact of the findings on respondents was also discussed.
\end{abstract}

KEYWORDS: Food neophobia, familiarity, willingness-to-try, sojourners, Malaysia local foods

\section{PURPOSE AND BACKGROUND}

Food neophobia is generally known as a personality trait of an individual, their acceptance or avoidance towards food that unfamiliar or new to them. (Education of Malaysia, 2019). For the past few years Malaysia have recruited many international students. These students can be called as sojourners. Sojourners might have a problem in consuming Malaysia food because they are not familiar with local food.

This will decrease their willingness-to-try due to certain thing such as food aversion and disgust. Since, these sojourners not familiar with Malaysia local foods, food neophobia levels among them are likely to be high. When food neophobia is high it will generally decrease the willingness-to-try novel foods (Loewen \& Pliner, 2000). Malaysia local foods will be novel foods towards these sojourners because they have never been exposed to Malaysian cuisine before.

High levels of food neophobia often mitigate consuming a nutritionally balanced diet (Edwards et al., 2010) and this may be harmful to the sojourners in the long run, they can become malnourished. However, there is limited research on sojourners' food consumption making it a challenge to learn about them. This study was carried out in order to provide additional knowledge on to levels of food neophobia among sojourners in Terengganu. 


\section{METHODOLOGY}

This cross-sectional study involving 152 international students of UMT and UniSZA at Gong Badak, Kuala Terengganu and Tembila. Purposive sampling was used to choose a group of respondents which match with the inclusion criteria. The researchers used a snowball sampling method asking international students directly where other international students could be found. The questionnaires were then distributed using a face-to-face approach and online via Google Forms. Google Forms was used to obtained international students at Tembila and Kuala Terengganu. Data collected were analysed by using the Statistical Package of Social Science (SPSS) Version 23.0. The statistical procedures involved descriptive test that covered on the mean and standard deviation, correlation test and lastly chi-square test according to the research objectives.

\section{FINDINGS}

The findings reported average food neophobia scale among sojourners in Terengganu was $40.15 \pm 12.21$. The value was quite high compared to the study that had been done by Choe, and Cho (2011) among Korean towards their non- traditional foods and studied by Olabi et al. (2009) among American and Lebanese students. The result obtained was a little higher compared to other studies, it showed that sojourners in Terengganu are more afraid to try unfamiliar foods. There was no significant difference between food neophobia and gender but there was a significant difference in the neophobia levels between residential areas (urban and rural), and the length of stay in Malaysia.

Sojourners who stayed in urban area have lower neophobic value compared to those who stay in rural area. Faccio and Nai-Fovino (2019) stated that urbanisation have a significant impact on food neophobia. This finding was supported by Guzek et al. (2018) who highlighted the fact that neophobic tendencies of those who live in urban areas are much lower compared to those who live in suburban areas.

Another study also stated that food neophobia among international students decreased with time, as they started to get familiar with the food the food neophobia also decreased (Edwards et al., 2010). It can be concluded that, the duration of exposure can affect food neophobia levels in an individual (Choe, and Cho, 2011).

Moreover, there were a significant association between food neophobia and familiarity towards Malaysia local foods. A significant association between food neophobia and willingness-to-try Malaysia local food also recorded. Besides, familiarity and food neophobia have strong negative correlation $\left(-0.770^{* *}\right)$, while willingness-to-try recorded a moderate negative relationship $\left(-0.529^{* *}\right)$ in non-stimulating circumstances and a weak positive $\left(0.168^{*}\right)$ relationship in stimulating circumstances.

\section{CONCLUSION}

The present study shows that FNS among sojourners in Terengganu was quite high where there were significant differences reported for residential area and length of staying in Malaysia towards food neophobia, while gender did not have significant impact on food neophobia.

Moreover, this study also indicated that there were significant association between food neophobia and familiarity, and food neophobia with willingness-to-try. Future studies should focus the related factor that affected the food neophobia such as the culture of the particular ethnic. 


\section{CONTRIBUTION/PRACTICAL IMPLICATIONS}

The study regarding food neophobia is particular vital because food neophobia have an impact on food preferences. Understanding the factors influencing food preferences is essential for the implementation and promotion of positive changes in the food habits of any society.

It also will help the food acculturation process among these sojourners, the faster their food acculturation process the better to obtain the restrictive diet. Moreover, this study also will expose local foods to the sojourners. This will increase the sojourners knowledge regarding the food and they will become more familiar. This will benefit Malaysia as other countries try and share Malaysian foods with their countrymen back home.

\section{ACKNOWLEDGEMENTS}

I would like to express my deep and sincere gratitude to my family, my supervisor Dr. Shukri. I would also like to thank Malaysian Government funding from Fundamental Research Grant Scheme FRGS 59589 [FRGS/1/2019/SS06/UMT/02/1] and all the participants that involved in this research.

\section{REFERENCES}

Choe, J. Y., \& Cho, M. S. (2011). Food neophobia and willingness to try non-traditional foods for Koreans. Journal of Food Quality and Preference, 22(7), 671-677.

Edwards, J. S. A., Hartwell, H. L., \& Brown, L. (2010). Changes in food neophobia and dietary habits of international students. Journal of Human Nutrition and Dietetics, 23(3), 301-311.

Olabi, A., Najm, N. E. O., Baghdadi, O. K., \& amp; Morton, J. M. (2009). Food neophobia levels of Lebanese and American college students. Journal of Food Quality and Preference, 20(5), 353-362. 